\title{
Complete atrial dissociation versus diaphragmatic action potentials
}

\author{
J. Soler-Soler and J. Angel-Ferrer \\ From Sección de Cardiología, Departamento de Medicina, Ciudad Sanitaria de la Seguridad Social, Barcelona, \\ Spain
}

Seven patients with severe respiratory insufficiency, whose electrocardiograms were suggestive of complete atrial dissociation, were studied. The $P^{\prime}$ waves clearly were not instrumental artefacts. The pneumograms proved that the $P^{\prime}$ waves were intimately related to inspiration, so that with voluntary apnoea the $P^{\prime}$ waves disappeared. The use of oesophageal leads $\left(E_{32}-E_{3} 8\right)$ failed to show $P^{\prime}$ waves; on the other hand, they were shown by leads that selectively explored the diaphragmatic region. The study suggests that the $P^{\prime}$ waves were not of atrial origin but represented the action potentials of the diaphragmatic muscle. The diagnosis of complete interatrial block, when the $P^{\prime}$ waves appear at a slow rate, can only be accepted when it has been shown that the $P^{\prime}$ waves are not related to respiratory movements.

In 1906, Wenckebach introduced the concept of interatrial dissociation. In 1920, Schrumpf published the first electrocardiogram of this arrhythmia. Since then numerous authors have described this arrhythmia with different names: 'double commande auriculaire' (Géraudel, 1934; Dominguez and Bizzozero, 1937), intra-atrial dissociation (Bellet, 1953), atrial dissociation (Bellet, 1963; Hayes and Kerby, 1964), and complete intra-atrial block (Scherf and Cohen, 1964; Schamroth, 197I). Cohen and Sherf (1965) described the coexistence of sinus rhythm and of an ectopic atrial rhythm ( $\mathrm{P}^{\prime}$ waves), with a frequency of discharge between 28 and 56 a minute, as the most typical form of complete intra-atrial block. Various authors (Deliyiannis and Salama, 1965; Higgins, Phillips, and Sumner, 1966; Aygen et al., 1972) have doubted the existence of this arrhythmia and particularly of the type with low frequency of the $\mathrm{P}^{\prime}$ waves, believing that in fact this is sinus rhythm with interference from respiratory function. This paper reports the study of 7 patients with an assumed complete intraatrial block in whom it is suggested that the $P^{\prime}$ waves correspond to the action potentials of the diaphragmatic muscle.

\section{Subjects and methods}

Seven patients were studied whose electrocardiograms (Fig. I) fulfil the criteria of Cohen and Scherf (1965) for Received 7 November 1973. the diagnosis of the most common form of complete intra-atrial block (rhythm of atrial origin, ventricular depolarization dependent on the atrial rhythm, and presence of $P^{\prime}$ waves totally independent and without ventricular capture). The patients were 5 men and 2 women, aged 25 to 74 (average 62). All the patients presented, at the time of taking the electrocardiogram, severe respiratory insufficiency; the aetiology was: 4 chronic obstructive lung disease, 2 pulmonary metastases (Krukenberg neoplasm and gastric adenocarcinoma), and I pulmonary thromboembolism. Apart from the 2 patients with neoplasia, they were all obese.

In all cases the electrocardiograms were recorded by at least 2 different machines, with 2 different power sources and in 2 different rooms. In all but one the electrocardiograms were taken within a few days of the discovery of the arrhythmia. In 6 cases the electrocardiograms were taken simultaneously with a pneumogram (Fig. 2) by means of a Boucke-Bretch infraton receptor connected to an Elema Schonander Mingograph. In 6 cases a bipolar lead VI-low VI and/or oesophageal leads were taken. In one case the intracavitary electrogram of the right atrium was taken.

\section{Results}

All the patients were in sinus rhythm with superimposed $P^{\prime}$ waves which were not related either to the $P$ waves or to the QRS complex. The frequency of the $P^{\prime}$ waves varied between 35 and 60 a minute (average 46). With the exception of the 2 cachectic patients, the $\mathbf{P}^{\prime}$ waves were only registered in leads II, III, and VF; moreover, in those 2 patients the 


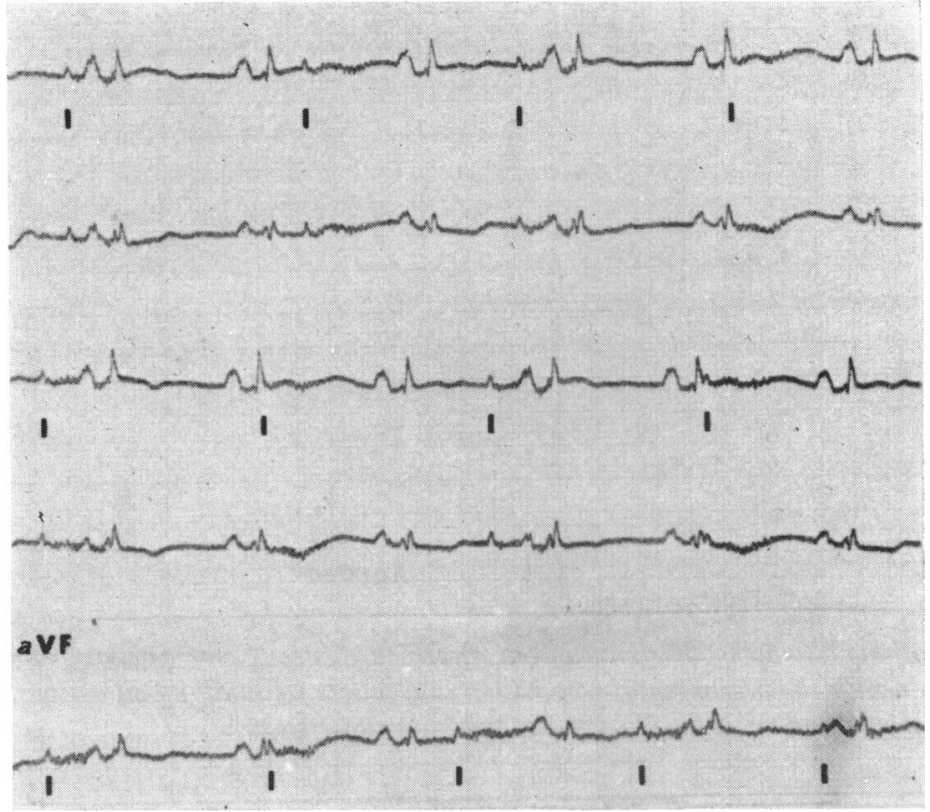

FIG. I Typical electrocardiogram of the so-called complete intra-atrial block with low frequency ( 42 to 45 per minute) of the $P^{\prime}$ waves (vertical lines). Observe that the $P^{\prime}$ waves are independent of the $P$ waves and the $Q R S$ complex, and are followed by a run of waves of high frequency of $0.40 \mathrm{sec}$ duration.

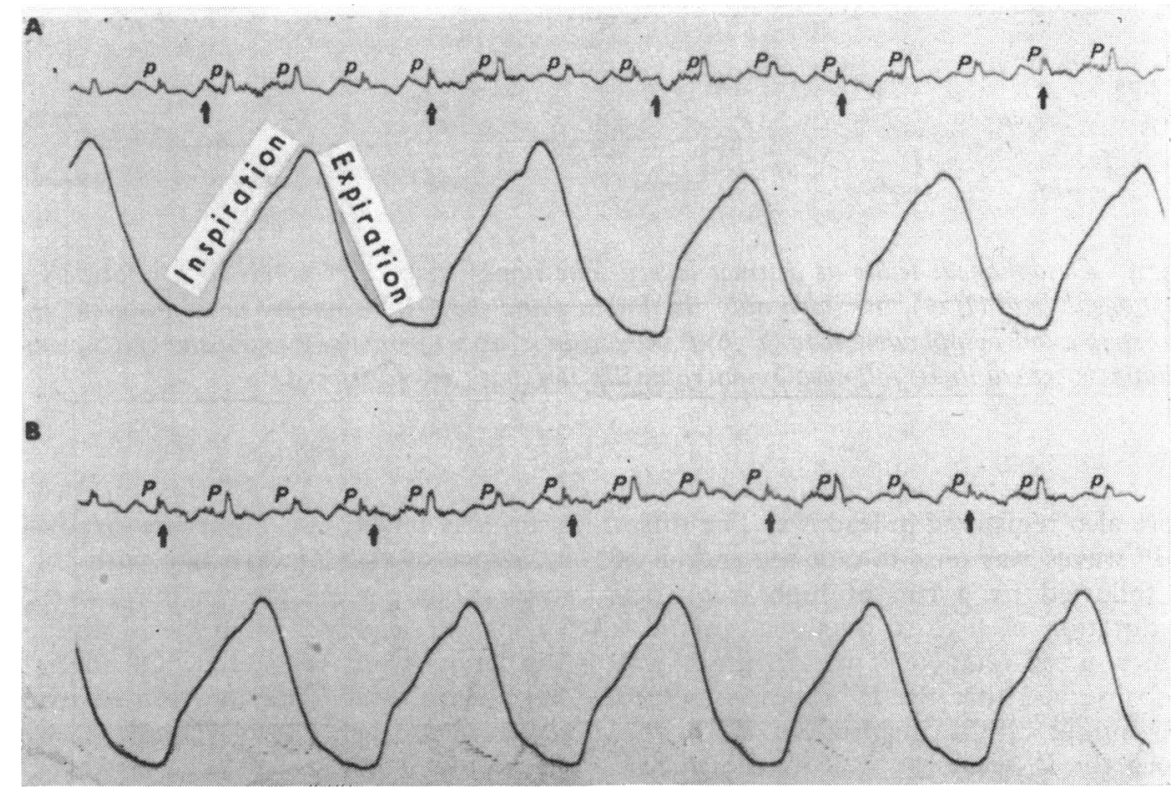

FIG. 2 Simultaneous electrocardiogram and pneumogram. Lead $V_{I}$-low $V_{I}:$ the $P^{\prime}$ waves (arrows) are registered exactly at the beginning of inspiration. The rhythm of the $P^{\prime}$ waves is irregular; the pneumogram faithfully follows the changes of frequency. 


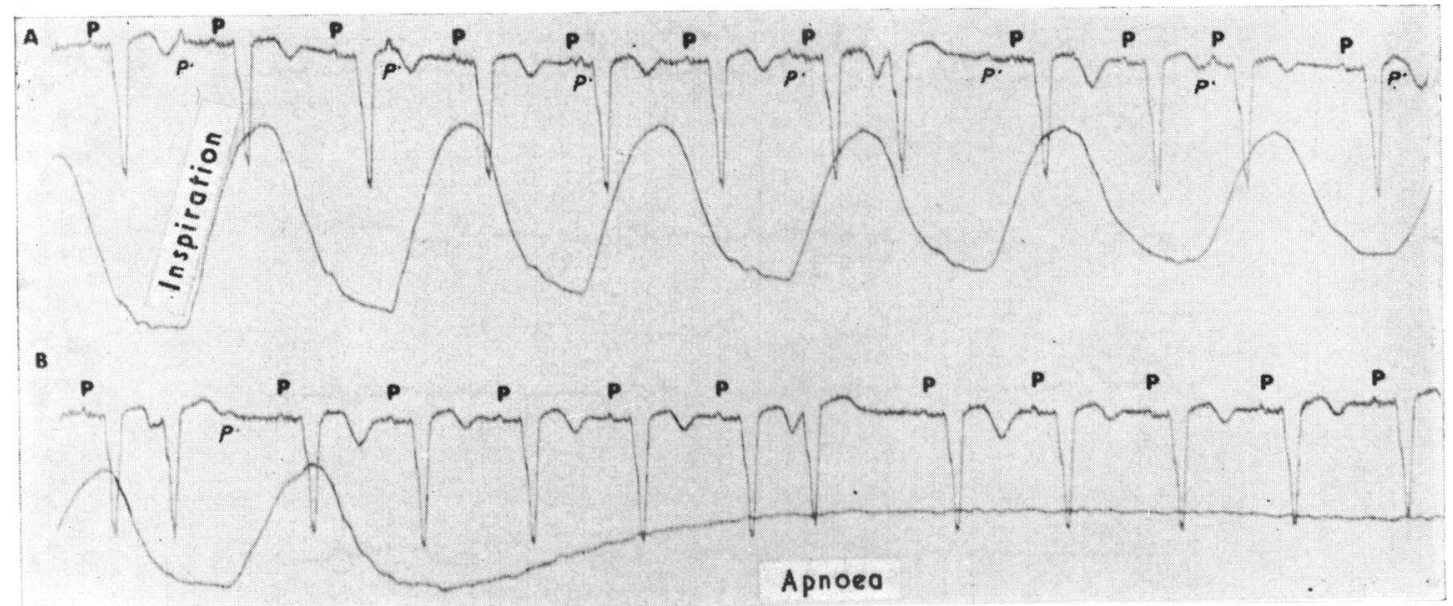

FIG. 3 Continuous tracing of simultaneous electrocardiogram and pneumogram. In $A$, the waves coincide with the beginning of inspiration and follow its small modifications of frequency. In $B$, the $P^{\prime}$ waves and microfibrillation disappear during apnoea.

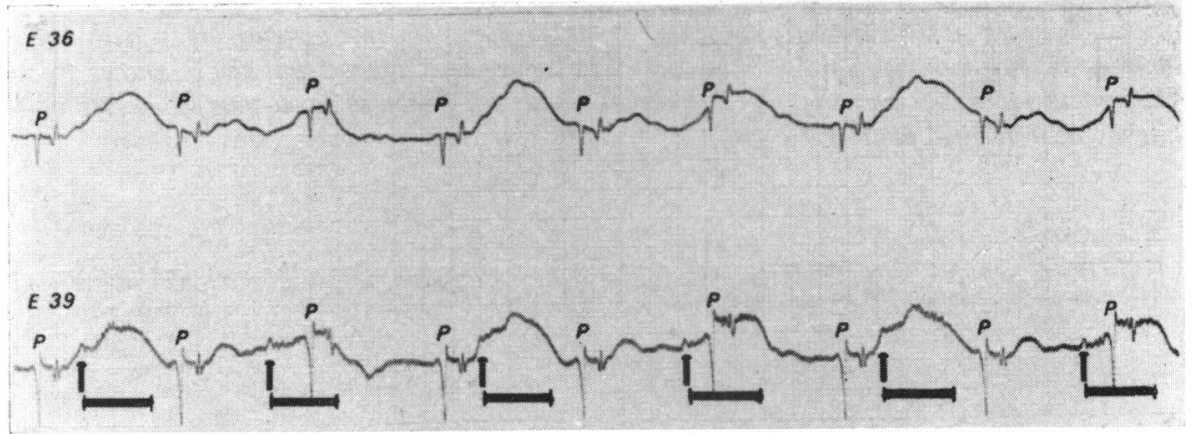

FIG. 4 Oesophageal leads at distinct levels. The upper strip corresponds to a relatively high oesophageal lead $\left(E_{36}\right)$, in which only the $P$ wave and the $Q R S$ complex are registered. In the lower strip a low oesophageal lead $\left(E_{39}\right)$ is shown; in it, apart from the $P$ wave and $Q R S$ complex, $P^{\prime}$ waves (vertical lines) followed by microfibrillation (bar) are registered.

$\mathrm{P}^{\prime}$ waves were also registered in lead VI. The duration of the $\mathrm{P}^{\prime}$ waves was 0.04 to $0.06 \mathrm{sec}$ and all of them were followed by a run of high frequency waves of a duration of 0.30 to $0.55 \mathrm{sec}$. In the 6 cases in which a simultaneous pneumogram was taken it was observed that the $\mathbf{P}^{\prime}$ waves coincided with the beginning of the inspiration. With voluntary apnoea the $\mathbf{P}^{\prime}$ waves as well as the microfibrillation always disappeared (Fig. 3). In the cases in which the respiration was not regular, the sequence of $\mathrm{P}^{\prime}$ waves followed the variations of respiration. In the only case in which no pneumo- gram was taken, two observers established the coincidence of the $\mathrm{P}^{\prime}$ wave rate with the number of respirations per minute. In the 3 cases in which a VI-low VI lead was taken the $P^{\prime}$ waves and microfibrillation were registered. Of the 4 cases with oesophageal leads none presented evidence of $P^{\prime}$ waves at the usual level (E32-E38) whereas leads placed much lower registered $\mathbf{P}^{\prime}$ waves and microfibrillation (Fig. 4). In the only case where an intracavitary electrogram of the right atrium was taken no $P^{\prime}$ wave was registered. The phenomenon lasted from $I$ to 20 days, with an average duration of 5 
days. The 2 patients with pulmonary metastases died 24 and 72 hours after the study, but the rest of the patients were alive three months later.

\section{Discussion}

Schamroth (1971) defines four types of complete intra-atrial block: sinus rhythm with an ectopic atrial rhythm, sinus rhythm with atrial fibrillation, sinus rhythm with atrial flutter, and a combination of atrial flutter and fibrillation. According to Chung (1968, 1970, 197I) the most frequent form is sinus rhythm with a slow atrial rhythm corresponding to the depolarization of the blocked atrial segment. Cohen and Scherf (1965) gave as the diagnostic criteria of complete intra-atrial block, the existence of a slow ectopic atrial rhythm not conducted to the ventricles, with a frequency of 28 to 54 a minute with the $\mathrm{P}^{\prime}$ waves followed by a run of waves of high frequency ( 500 to $3000 / \mathrm{sec}$ ) of less than I sec duration and which is independent of this sinus rhythm acting as pacemaker. These authors pointed out the possibility that this could be an extracardiac phenomenon, but rejected this idea and suggested that the run of waves that follows the $\mathbf{P}^{\prime}$ waves represented the microfibrillation of the blocked atrial segment. Igarashi, Katayama, and Hinohara (1963) published 2 cases of supposed atrial dissociation: in one of them they could not register $P^{\prime}$ waves with an oesophageal lead. Higgins et al. (1966) demonstrated that the $P^{\prime}$ waves and microfibrillation coincided with the beginning of inspiration, attributing such electrical phenomenon to the electromyogram of the accessory respiratory muscles. Aygen et al. (1972) took the electromyogram of those muscles and showed that they were not responsible for the $\mathrm{P}^{\prime}$ waves; these authors, in an experimental work with cats, reproduced the phenomenon by means of phrenic stimulation and suggested that the origin of the $\mathbf{P}^{\prime}$ waves is in the diaphragmatic muscle. We, in our 7 cases, excluded the possibility of external interference influencing the electrocardiograms. In spite of the fact that the oesophagus is a good place for the registration of an atrial electrogram (Kistin and Bruce, 1957; Attie and Hamdan, 1964; Valle et al., 1969), in none of the 4 cases studied were the $P^{\prime}$ waves and/or microfibrillation obtained at the usual level (E32-E38) but were found at much lower positions of the catheter; for this reason we think it is highly improbable that the $\mathrm{P}^{\prime}$ waves originate in the atria. This idea is also supported by the only case in which the intracavitary electrogram of the right atrium failed to demonstrate $P^{\prime}$ waves. The fact that this arrhythmia appears in patients with severe respiratory insufficiency and the $\mathrm{P}^{\prime}$ waves always coincided with inspiration and followed its changes indicates that one is dealing with a phenomenon related to respiration. As well as Aygen et al. (1972), we believe that the $\mathrm{P}^{\prime}$ waves and the microfibrillation represent the action potentials of the diaphragmatic muscle. It is suggested that the action potentials of the diaphragmatic muscle can simulate complete intra-atrial block type I of Schamroth (I97I) when the ectopic atrial rhythm has a slow frequency; before making this diagnosis one must consider this possibility. The recording of the action potentials of the diaphragmatic muscle on the surface electrocardiogram does not mean a poor prognosis, in contrast with the findings of other authors (Giraud, Jouve, and Senez, 1943; Deitz et al., 1957; Chung, 1971) who studied authentic cases of complete intraatrial block.

\section{Conclusions}

I) The diagnosis of complete intra-atrial block should be doubted when the frequency of the $\mathrm{P}^{\prime}$ waves is between 30 and 60 per minute.

2) In order to establish the diagnosis of complete intra-atrial block, one must exclude external interference influencing the patient and demonstrate that the $\mathrm{P}^{\prime}$ waves are not related to respiratory movements.

3) Correspondence of the $P^{\prime}$ waves with inspiration is highly suggestive that they represent the action potentials of the diaphragmatic musculature.

4) The presence of the action potentials of the diaphragmatic muscle in the electrocardiogram does not imply, per se, a poor prognosis.

\section{References}

Attie, F., and Hamdan, G. (1964). El valor de la derivación esofágica en el diagnóstico diferencial de las taquicardias. Archivos del Instituto de Cardiología de México, 34, 82.

Aygen, M. M., Manoach, M., Liberman, U. A., Mintz, U., and Savransky, H (1972). Diaphragmatic action potentials registered in the electrocardiogram: a clinical and experimental study. American Heart fournal, 83, 630.

Bellet, S. (1953). Clinical Disorders of the Heart Beat. Lea and Febiger, Philadelphia.

Bellet, S. (1963). Clinical Disorders of the Heart Beat 2nd ed. Lea and Febiger, Philadelphia; Kimpton, London.

Chung, E. K. Y. (1968). Parasystole. Progress in Cardiovascular Diseases, 11,64 .

Chung, E. K. Y. (1970). Diagnosis and clinical significance of atrial dissociation. In Symposium on Cardiac Arrhythmias, p. 183. Ed. by E. Sandoe, E. Flensted-Jensen, and K. H. Olesen. AB Astra, Söderstälje, Sweden.

Chung, E. K. Y. (I97I). A reappraisal of atrial dissociation. American fournal of Cardiology, 28, I I I.

Cohen, J., and Scherf, D. (1965). Complete interatrial and intra-atrial block (atrial dissociation). American Heart Fournal, 70, 23.

Deitz, G. W., Marriott, H. J. L., Fletchner, E., and Bellet, S. (1957). Atrial dissociation and unilateral fibrillation. Circulation, 15, 883. 
Deliyiannis, S. J., and Salama, I. A. (1965). Electrocardiographic recording of diaphragmatic action potential. American Heart fournal, 69, 497.

Dominguez, C., and Bizzozero, R. C. (1937). Double commande auriculaire. Archives des Maladies du Couer et des Vaisseaux, 30, 820 .

Geraudel, E. (1934). Le double commande intégrale. Contribution á l'étude du mécanisme cardiaque. Archives des Maladies du Coeur et des Vaisseaux, 27, 524.

Giraud, P., Jouve, A., and Senez, J. (1943). Dissociation transitoire des oreillettes au cours d'une diphtérie maligne. Archives des Maladies du Coeur et des Vaisseaux, 36, 21.

Hayes, W. L., and Kerby, G. R. (1964). Atrial dissociation. American Heart fournal, 68, 252.

Higgins, T. G., Phillips, J. H., and Sumner, R. G. (1966). Atrial dissociation. An electrocardiographic artifact produced by the accessory muscles of respiration. American Fournal of Cardiology, 18, 132.

Igarashi, M., Katayama, F., and Hinohara, S. (1963). Two cases of atrial dissociation. American fournal of Cardiology, II, 267.

Kistin, A. D., and Bruce, J. C. (1957). Simultaneous esophageal and standard electrocardiographic leads for the study of cardiac arrhythmias. American Hear ifournal, 53, 65.

Schamroth, L. (1971). The Disorders of Cardiac Rhythm, p. 216. Blackwell Scientific Publications, Oxford and Edinburgh.

Scherf, D., and Cohen, J. (1964). The Atrioventricular Node and Selected Cardiac Arrhythmias, p. 352. Grune and Stratton, New York and London.

Schrumpf, P. (1920). De l'interference de deux rythms sinusaux; preuve du dualisme du nodule de Keith. Archives des Maladies du Coeur et des Vaisseaux, 13, 168 .

Valle, V., Revuelta, J. M., Montoyo, J. V., Pérez, S., and Gausí, C. (1969). Utilidad de la derivación esofágica en el diagnóstico de las arritmias. Actas Cardiovasculares, 2, 153.

Wenckebach, K. F. (1906). Beitrage zur Kenntnis der menschlichen Herztätigkeit. Archiv fur Physiologie, 297.

Requests for reprints to Dr. J. Soler-Soler, Sección de Cardiologia, Departamento de Medicina, Ciudad Sanitaria de la Seguridad Social, Paseo Valle de Hebrón, s/n, Barcelona - 16, Spain. 